\title{
Instruments and Methods for Identifying Indicators of a Digital Entrepreneurial System
}

\author{
Jelena Raut ${ }^{1}$, Đorđe Ćelić ${ }^{1, *}{ }^{\mathbb{C}}$, Branislav Dudić ${ }^{2,3, * \mathbb{C}}$, Jelena Ćulibrk ${ }^{1}$ and Darko Stefanović ${ }^{1}$ (i) \\ 1 Faculty of Technical Sciences, University of Novi Sad, 21000 Novi Sad, Serbia; jelenaraut@uns.ac.rs (J.R.); \\ jculibrk@uns.ac.rs (J.Ć.); darko.stefanovic@uns.ac.rs (D.S.) \\ 2 Faculty of Management, Comenius University in Bratislava, 82005 Bratislava, Slovakia \\ 3 Faculty of Economics and Engineering Management, University Business Academy, 21000 Novi Sad, Serbia \\ * Correspondence: celic@uns.ac.rs (Đ.Ć.); branislav.dudic@fm.uniba.sk (B.D.)
}

Citation: Raut, J.; Ćelić, Đ.; Dudić, B.; Culibrk, J.; Stefanović, D. Instruments and Methods for Identifying Indicators of a Digital Entrepreneurial System. Mathematics 2021, 9, 2151. https://doi.org/10.3390/math9172151

Academic Editor: Cristina Raluca Gh. Popescu

Received: 22 July 2021

Accepted: 30 August 2021

Published: 3 September 2021

Publisher's Note: MDPI stays neutral with regard to jurisdictional claims in published maps and institutional affiliations.

Copyright: () 2021 by the authors. Licensee MDPI, Basel, Switzerland. This article is an open access article distributed under the terms and conditions of the Creative Commons Attribution (CC BY) license (https:// creativecommons.org/licenses/by/ $4.0 /)$.

\begin{abstract}
Entrepreneurial ecosystems are the main driver of the widespread trend of digitalization, and they open opportunities for the advancement of the digital economy. The digital economy makes its progress through innovative enterprises that can ensure global progress. In order to effectively use the opportunities that open up the process of digitalization, information is needed on how much the Republic of Serbia is able to support the process of discovering entrepreneurship, which is stimulated by digitalization, which is the subject of this paper. The aim of this paper is to analyze the digital entrepreneurial system of the Republic of Serbia, as well as to identify indicators that hinder the development of this system, using appropriate instruments and methods that will be presented in detail in the paper. The results have demonstrated that the starting point for improvement of the digital entrepreneurial system is in the field of finance, with a particular focus on companies in the startup and stand-up phases. Furthermore, a comparative analysis will showcase the digital entrepreneurial system of the Republic of Serbia and the member states of the European Union, where it will be seen that the digital entrepreneurial system of the Republic of Serbia is lagging behind the member states of the European Union in its growth and development. The results will serve as the starting point for policymakers to improve the process of digitalization and the digital entrepreneurial system as a whole. The results show the starting point for the improvement of entrepreneurship in the Republic of Serbia, that is, how small, and medium-sized enterprises can be encouraged on the path to their successful management.
\end{abstract}

Keywords: digital entrepreneurial ecosystem; digital technologies; digital entrepreneurship; digital systems; innovations; small and medium-sized enterprises

\section{Introduction}

Digitalization is a process to which a lot of scientific research is dedicated, and it is essential because it shapes the nature and location of entrepreneurial opportunities. The development of digitalization has encouraged the global adoption of new organizational innovations, which will support entrepreneurial opportunities The table must appear after the citation in the main text1]. With the development of digitalization, a new type of regional agglomeration of economic activities is developing, identified as an entrepreneurial ecosystem [1].

Digitalization is a process that is of defining importance for entrepreneurial ecosystems. Digitalization enables digital technologies and digital infrastructures to be woven into the economy and society [2]. Two crucial characteristics of digital technologies and infrastructures stand out, which help to explain the transformational impact they have on innovation and entrepreneurship. The first significant characteristic is that digital technologies and infrastructures have a general purpose. They can be applied in almost all sectors, functions, and activities, potentially transforming them [3]. The second important characteristic is that digital technologies and digital infrastructures disclose entirely new ways of 
organizing. When these two characteristics are combined, they make digital technologies and digital infrastructures more powerful, at the same time facilitating innovation of business models [4]. Thus, it can be concluded that digitalization is a process that conditions certain changes in the economy by enabling the execution of entirely new processes or the execution of existing processes, in a significantly different way, which in most cases is more efficient than the former. It is precisely these dynamics that are digitally enabled and that emerge with the discovery of new business models that make entrepreneurial ventures become a central driver of the development of the digital economy and allow for the unlocking of the full productivity potential [4].

Digital entrepreneurship is a category of entrepreneurship, which is accomplished by taking advantage of digital technologies and digital infrastructures. Digital entrepreneurship can be defined as the digitalization of one or more predefined business models by entrepreneurs in terms of distribution and workplace [5]. Furthermore, digital entrepreneurship is a subcategory of entrepreneurship, which should be physically digitalized in a traditional organization [6]. Digital entrepreneurship is an attempt by the current entrepreneurial environment to adapt to the needs of the digital age in the context of developmental and changing conditions [7]. Digital entrepreneurship is also a search for opportunities through digital media and other information and communication technologies [8]. Digital entrepreneurship can also be defined as the encounter of digital information and technology with entrepreneurs. An entrepreneur is a person who uses the internet to create commercial opportunities, disseminate information, cooperate with customers or partners [9]. Due to its great importance, digitalization is included in research and encompasses the conditions of digitalization that are binding throughout the country.

The components that make up the entrepreneurial ecosystem greatly influence the shaping of digital entrepreneurship. Entrepreneurial ecosystems encourage entrepreneurs to generate ideas, identify and allocate resources, and take advantage of the opportunities provided by the digital marketplace, where they will gather information and create legitimacy for innovation [5].

The entrepreneurial ecosystem has emerged as an entirely new cluster type to support the digital dynamics of discovering a new business model [10]. The entrepreneurial ecosystem represents the community of all stakeholders who specialize in facilitating the improvement of business models. A brief literature review suggests a view of entrepreneurial ecosystems as a new cluster type that characterizes the digital economy.

The latest evolution in entrepreneurial policy emphasizes a holistic and multifaceted view of entrepreneurship, where the entrepreneurial ecosystem emerges as a result. A holistic approach to entrepreneurship focuses on the individual, personality, and behavior, contributing to a better understanding of entrepreneurial activity [11-13]. Furthermore, a holistic approach advocates the research of entrepreneurial activity, not focusing on entrepreneurial activities in isolation, but as individual behavior of entrepreneurs, which is embedded in the local context [14-16]. The focus on entrepreneurial ecosystems draws attention to policies and initiatives for entrepreneurship throughout the life cycle of an entrepreneurial venture. Support for entrepreneurship must be viewed in a broader regional context [17]. As stated in the REDI (The Regional Entrepreneurship and Development Index) Measuring Regional Entrepreneurship Final Report, the concepts of the entrepreneurial ecosystem and the entrepreneurship system are very similar. However, the difference is that entrepreneurial ecosystems focus on policies and initiatives to support entrepreneurship from policy perspectives. In contrast, entrepreneurship systems focus on the entrepreneurial dynamics that drive productivity growth in the region [12].

The entrepreneurial ecosystem can be defined as a new way of contextualizing more complex social systems [18]. A system is an organized set of interactive and interdependent systems functioning as a whole to achieve a specific purpose. At the same time, an ecosystem is a purposeful network of dynamic and interactive systems and subsystems that have a variable set of privacy in today's context [19]. The entrepreneurial ecosystem consists of subsystems integrated into systems, which can be optimized for system performance at the 
ecosystem level [20]. According to the authors of the Global Entrepreneurship Index powered by GEDI, the concept of the entrepreneurship system is based on three premises, which provide a starting point for the analysis of the entrepreneurial ecosystem [20]. The first premise is based on the fact that entrepreneurship is based on actions taken and led by individuals, based on incentives; the second premise argues that individual action is affected by framework conditions; while the third premise claims that ecosystems are complex, multilayered structures in which many elements interact and affect system performance.

Entrepreneurial ecosystems can also be defined at the socio-economic level, where they have the properties of self-organization, scalability, and sustainability as "dynamic institutional policy, built-in interaction between entrepreneurial attitudes, abilities, and aspirations by individuals, which drive resource allocation through creating and launching new ventures" [21]. Entrepreneurial ecosystems are complex socio-economic structures, which revive the actions of individual levels, where a lot of knowledge is relevant to entrepreneurial activity and is built into the structures of ecosystems, and require action at the individual level. Entrepreneurial ecosystems are also defined as resource allocation systems, which facilitate the allocation of resources according to productive use [22]. The widespread trend of digitalization plays a significant role in the advancement of entrepreneurial ecosystems, which opens the possibility for every organization to reconsider value creation activities in the economy through business model innovations. This very feature enables entrepreneurial ecosystems to become a key driver of progress towards a digital economy.

Digitalization is a process that reorganizes the business activities of a company and the entire society around digital technologies and digital infrastructure. The entrepreneurial ecosystem represents a new form of regional joining of entrepreneurial activities, which supports the process of discovering new radical business models, which are a challenge for existing companies [4]. This is a unique entrepreneurial challenge that, in a way, conditions companies to adopt new and more efficient practices. That is why entrepreneurial ecosystems are significant for improving the productivity potential of the digital economy.

The authors of this paper focused on the analysis of the digital entrepreneurial system of the Republic of Serbia, based on the report The European Index of Digital Entrepreneurial Systems (EIDES), to make recommendations for more effective policies for progress towards the digital economy, based on research pertaining to the degree of Serbia's ability to support the process of discovering entrepreneurship encouraged by digitalization. Within the EIDES report, the Republic of Serbia was not included in the research.

In every digital entrepreneurial system, there are stakeholders, which differ from one digital entrepreneurial system to another, as well as other elements that create certain results within the system, i.e., innovative companies that compete with each other with their digitally improved business models. These companies provide an "economic service" through which they improve the digital economy by reorganizing their businesses and creating new values. This is another reason the authors decided to lay the foundation of the research based on the EIDES report, because it was designed to cover all aspects of this fundamental dynamic.

At the very end, the authors will conclude which elements of the digital entrepreneurial system of the Republic of Serbia are the least developed and thus present to policymakers what are the "bottlenecks" that hinder the development of the digital entrepreneurial system. After that, the weakest pillar of the digital entrepreneurial system of the Republic of Serbia will be identified, and a comparative analysis of the digital entrepreneurial system of the Republic of Serbia with the member states of the European Union will be presented through the digital aspect of the observed systems.

The purpose of this paper is to diagnose the digital entrepreneurial system of the Republic of Serbia based on its current state, according to the EIDES report, based on which can be concluded what the recommendations for the starting point for its improvement are. As the authors of the EIDES report recommend, the starting points for improving 
any digital entrepreneurial system are the indicators that slow it down most and hinder its development.

After the introduction, the second part of this paper will present in detail the structure of the digital entrepreneurship system according to the EIDES report, focusing on the digital dimension of the digital entrepreneurship system. Then, in the third part, attention is paid to a detailed description of the methodology, through a description of the research questions, the research sample, and the research instruments. The fourth part focuses on the identification of indicators of the digital entrepreneurial system of the Republic of Serbia that hinder and slow down its development, as well as the presentation of the mathematical calculation which results in the formation of pillars of the digital entrepreneurial system and the identification of the pillar that slows down the development of the digital entrepreneurial system. The fifth part presents a comparative analysis of the digital entrepreneurship system of the Republic of Serbia and digital entrepreneurship systems of EU member states, according to the EIDES report, to conclude whether the Republic of Serbia lags behind in the development of its digital entrepreneurship system. In the final, sixth part, the authors focused on the importance of the analysis as a potential improvement of the regional development of the Republic of Serbia.

\section{Materials and Methods}

\subsection{Research Method}

The European Index of Digital Entrepreneurship Systems was first analyzed in a 2018 report [23]. After that, on the same basis, a report for 2019 was prepared [1]. It provides evidence-based support for digital innovation policies and the launch of new reports. When comparing the 2018 and 2019 reports, the 2019 index structure has been adjusted in response to changes in available data. The names of the sub-indexes and pillars of the digital entrepreneurial system have remained the same. However, their variables and the composition of the indicators differ in relation to the 2018 edition.

The authors of the EIDES 2019 report define entrepreneurial ecosystems as follows: "An entrepreneurial ecosystem is a regional community of entrepreneurs, advisors, accelerators and other stakeholders and specialized resources, which support entrepreneurial stand-up, startup and scale-up and entrepreneurial opportunities in the search for digital business models" [1]. This digital entrepreneurial transformation of the economy is very challenging for politics.

The European Index of Digital Entrepreneurship System monitors three groups of conditions in $28 \mathrm{EU}$ member states. However, as mentioned in the introduction, the Republic of Serbia is not a member state and is not covered by the report, which is why the authors chose to focus on the analysis of the entrepreneurial system of the Republic of Serbia.

The European Index of Digital Entrepreneurship Systems monitors three groups of conditions:

- General framework conditions, which describe the context of conducting business in an observed country;

- Systemic framework conditions, which are directly related to entrepreneurial stand-up, startup and scale-up;

- Digital conditions (through the general framework and system framework conditions, i.e., through their digital dimension), which describe the general level of digitalization of an economy because they relate to entrepreneurial activities through the impact on general framework and system framework conditions [1].

The paper's authors focused on analyzing digital conditions, which will be explained in more detail below. The authors of the EIDES report explained precisely how the digital could be distinguished from the non-digital dimension of any entrepreneurial ecosystem, which is analyzed according to their methodology. Namely, when forming the methodology, as previously explained, all indicators are grouped into four large groups: general framework conditions, system framework conditions, digital framework conditions, and digital system conditions. Each of these groups of conditions consists of their associated 
pillars, as will be explained below. Each pillar is observed in both non-digital and digital dimensions. For example, the pillar of the digital entrepreneurial ecosystem, "culture and informal institutions," is part of the general framework conditions. This pillar can be analyzed in the non-digital dimension and is defined by a specific group of questions from the questionnaire explained below and a particular group of indicators, which correspond to the non-digital dimension of this pillar.

On the other hand, to analyze the pillar "culture and informal institutions" in the digital dimension, it is defined by another group of questions and another group of indicators, which corresponds to the digital dimension, according to the authors of the EIDES report. For the analysis to be relevant, at the very beginning, each pillar of the digital entrepreneurial system must be viewed together with its defining indicators, i.e., it must be considered both in its non-digital and digital dimension, to determine a statistically significant difference between $t$-test and ANOVA observed categories, i.e., pillars of the digital entrepreneurial system. After that prerequisite for further analysis, based on the obtained results, researchers can dedicate themselves to the analysis of the pillars of the digital entrepreneurial system, the analysis of the non-digital dimension, or the analysis of the digital dimension of the digital entrepreneurial system. The paper's authors decided to focus on the digital dimension of the digital entrepreneurial system due to the importance of digitalization in modern business.

The complete concept of The European Index of Digital Entrepreneurship Systems is based on the literature on entrepreneurial ecosystems. The idea of entrepreneurial ecosystems is a new approach, and it can be concluded that there is a relatively weak theoretical basis, which still brings some ambiguities to its concept. The main strength of an entrepreneurial ecosystem lies in its ability to fit many elements of the entrepreneurial context, emphasizing the close relationships and interdependence of these elements to strengthen entrepreneurial mechanisms through different parts of the entrepreneurial ecosystem [24]. The essence of entrepreneurial ecosystems is to take advantage of as many digital benefits as possible, which result from the rapid progress of digital technologies and digital infrastructures, which enable the innovation of business models.

The authors of the EIDES report adopted the concept of an "entrepreneurship system" to distinguish between the unit of analysis at the state level and the unit of analysis at the regional level [22]. The literature on entrepreneurial ecosystems is the most appropriate for understanding digital systems. At the same time, the authors of the EIDES report also emphasize that the analysis at the state level is not relevant.

The EIDES research includes 16 pillars, i.e., 4 pillars derived based on 4 groups within the general framework conditions and 12 pillars that are derived based on system framework conditions, due to differentiation through 3 life phases of the enterprise cycle. The authors of this paper did not focus on a complete analysis of the entrepreneurship system at the level of the state of the Republic of Serbia, based on the EIDES report, but only on its digital conditions.

\subsection{Participants}

For the purposes of this study, 16 faculties from the territory of the Republic of Serbia were randomly selected to participate in the research. Employees at the faculties were contacted, as well as doctoral students via e-mail, where the questionnaire distribution process was performed according to Dillman's approach [25]. A total of 950 questionnaires were sent, as well as follow-up e-mail reminders, where needed. After 3 months, out of 659 questionnaires received, 300 questionnaires were valid, so that this study includes 300 respondents, of which 136 are women and 154 men, from faculties in the territory of the Republic of Serbia. The sample of 300 respondents from different universities from the territory of the Republic of Serbia seems to be a representative sample. The sample consists of respondents who are doctoral students, researchers, and employees in higher education institutions because they are people who require new scientific information for their doctoral dissertations, which are often related to establishing new companies, 
creating new or by improving existing business processes, which are vastly more efficient and effective than existing ones, that is, they are related to innovations that can potentially enhance processes in modern business, and thus affect the improvement of the digital entrepreneurial system.

\subsection{Data Sample}

At the very beginning, a questionnaire and a matrix of all necessary indicators were formed, based on the EIDES report, with the researchers, i.e., the authors adding demographic characteristics and questions about potentially established companies by the respondents [1]. The formation of a questionnaire and matrix with all indicators is essential because it is the only way to adequately arrive at the indicators that slow down the development of the digital entrepreneurial system of the Republic of Serbia.

The questionnaire was sent to employees and doctoral students from the following universities: University of Belgrade, University of Novi Sad, University of Kragujevac, University of Novi Pazar, University of Niš, University of Arts in Belgrade, University of Priština, with temporary headquarters in Kosovska Mitrovica, University of Defense in Belgrade, Alpha BK University, Business Academy University, International University of Novi Pazar, Metropolitan University, Singidunum University, Union University, Educons University, Union-Nikola Tesla University and John Nesbit University.

This research sample was made because employees in higher education institutions and doctoral students are people who very often have innovative ideas that result in starting entrepreneurial companies.

The questionnaire was formed on the LimeSurvey platform and delivered to the respondents electronically. The research was conducted in the period from 1 February 2021 to 1 May 2021.

Respondents were told that the questionnaire was completely anonymous, that they did not need to provide their personal information anywhere, nor that the records of their answers would contain information that could reveal their identity, and that all their answers would be used only for scientific research purposes.

The questionnaire consisted of 47 questions, which were divided into 3 groups: a group referring to demographic data, a group asking about companies potentially established by respondents and their statement whether they are employed or self-employed as well as which alternative they prefer, and a group of questions based on the EIDES questionnaire.

After the answers from the questionnaire were processed, the results from the first group of questions were obtained; that is, the demographic structure of the respondents was formed. The study involved 300 respondents, of which the most significant number belong to the 31 to 40 age group, or $33.67 \%$, while only one respondent belongs to the 18 to 20 age group and only one respondent belongs to the group of respondents aged $71+$, which makes a total of $0.66 \%$ of respondents. In the sample, $45.33 \%$ were women and $54.67 \%$ were men. The most significant number of respondents completed doctoral studies, i.e., $76.67 \%$ of respondents. When it comes to the respondents' field of study, the most significant number belong to the technical and technological field, i.e., $53 \%$ of respondents. A total of $39 \%$ of respondents are from the University of Novi Sad, while $35.67 \%$ are from the University of Belgrade.

When it comes to the second group of questions, $3 \%$ of respondents said they were "students," $19 \%$ of respondents said they were employed in a for-profit organization, $27.67 \%$ of respondents were employed in a non-profit organization, $15 \%$ of respondents were employed in local or state administration, $4.33 \%$ of respondents were self-employed, i.e., own their own company. Furthermore, $72.33 \%$ of respondents stated that they prefer to be employed, compared to $27.67 \%$ who prefer to be self-employed. A total of $84.33 \%$ of respondents had not started a company. In comparison, $7.33 \%$ of respondents answered that the companies they own have existed on the market for up to 5 years, $3 \%$ of respondents said their companies have existed between 5 and 10 years, and $5.33 \%$ of respondents said they founded a company that has been on the market for more than 10 years. 
The last, i.e., the third group of questions, was made based on EIDES research and consisted of 36 questions, where, for each statement, respondents were asked to indicate a number that represents the degree of their agreement or disagreement with a statement on a Likert seven-point scale, which was adjusted to the research.

After that, the authors focused on a detailed analysis of the indicators that are the subject of research in this paper, which can be seen below.

\subsection{Research Question and Methodology Development}

The research is rooted in the basics of the EIDES research, i.e., The European Index of Digital Entrepreneurship Systems, from 2019 [1]. The EIDES report is the basis for the formation of the questionnaire used in the research and for the formation of the matrix, which consists of appropriate indicators and questions from the questionnaire, which provided the basis for evaluation of each pillar in the digital entrepreneurial system of the Republic of Serbia, as well as the basis for pinpointing the advantages and disadvantages of each pillar, which will be explained in more detail below.

The authors decided to focus in detail on the analysis of digital conditions. They observed general framework conditions through non-digital and digital dimensions combined, as well as systemic framework conditions through digital and non-digital dimensions combined to conduct adequate analyses that represent the baseline for further analysis.

General framework conditions consist of 4 pillars:

- Culture and informal institutions;

- Formal institutions, regulations and taxation;

- Market conditions;

- Physical infrastructure.

Systemic framework conditions encompass 4 pillars:

- Human capital;

- Knowledge creation and dissemination;

- Finance;

- Networking and support.

Based on the above, the following research questions were raised:

- RQ1: What are the least developed indicators in the digital dimension of the digital entrepreneurial system of the Republic of Serbia?

- RQ2: What is the least developed category, that is, the pillar of the digital entrepreneurial system of the Republic of Serbia?

Later, when adequate analyses are conducted, and it is determined between which of the above eight categories there is a statistically significant difference, the focus will be placed on the digital dimension of the digital entrepreneurial system of the Republic of Serbia.

\section{Results}

3.1. Identification of Indicators in the Digital Dimension of Digital Entrepreneurial Systems of the Republic of Serbia

General framework conditions and systemic framework conditions are considered together below, in their non-digital and digital dimensions, to see if and between which pillars of the digital entrepreneurial system of the Republic of Serbia there is a statistically significant difference, which will provide a basis for further detailed analysis.

At the very beginning of the research, the $t$-test assessed whether there is a statistically significant difference between the two groups of indicators: the first group of indicators are general framework conditions with general digital conditions, while the second group of indicators includes systemic framework conditions with systemic digital conditions. Considering that $p$-value $=0.001$, regarding $p$-value $<0.05$, it is concluded that there is a statistically significant difference between these two groups of indicators. The calculation of the mean value supports the conclusion that there is a statistically significant difference 
between these two groups of indicators, with the additional conclusion that the first group of indicators has a higher mean value compared to the second group, which would mean that the first group of indicators, the General Framework Conditions, in its non-digital and digital dimension, is more developed compared to the second group of indicators, i.e., systemic framework conditions, in its non-digital and digital dimension.

After the $t$-test, ANOVA was used. ANOVA, like the $t$-test, assesses whether there is a statistically significant difference in the mean values of the categories that are being compared, with the $t$-test being able to compare only two categories, while with ANOVA, three or more categories can be compared. With this in mind, ANOVA was used for variables with four and eight categories, which can be seen below.

It was first tested whether there was a statistically significant difference between the categories that make up the general framework conditions, in their non-digital and digital dimension, and the systemic framework conditions, in their non-digital dimension.

General framework conditions consist of the following categories:

- Culture, informal institutions;

- Formal institutions, regulation, taxation;

- Market conditions;

- Physical infrastructure.

Systemic framework conditions consists of the following categories:

- Human capital;

- Knowledge creation and dissemination;

- Finance;

- Networking and support.

As the EIDES report made a detailed matrix of which indicators each category consists of, the paper's authors were guided by it in researching and interpreting the results [1].

Before the ANOVA test, a test of homogeneity of variances was performed first to confirm that the variances within each group were homogeneous. Based on the homogeneity test, it was concluded that the variances are homogeneous because Sig. $=0.376$.

Then, the ANOVA test was performed. It was concluded that there is a statistically significant difference between the eight categories mentioned above regarding the indicator's values because Sig. $=0.011$, or Sig. $<0.05$.

After that, a post hoc test was performed, which served to show between which categories there is a statistically significant difference, and the post hoc test was chosen based on the obtained conclusion that the variances are homogeneous. The LSD post hoc test was selected, the results of which are shown in Table 1.

Table 1. Results of post hoc test.

\begin{tabular}{ccc}
\hline Category 1 & Category 2 & $p$-Value \\
\hline Culture, informal institutions & Market conditions & 0.02 \\
Culture, informal institutions & Human capital & 0.01 \\
Culture, informal institutions & Knowledge creation and dissemination & 0.00 \\
Culture, informal institutions & Finance & 0.00 \\
Culture, informal institutions & Networking and support & 0.02 \\
Formal institutions, regulations, taxation & Finance & 0.02 \\
Physical infrastructure & Finance & 0.02 \\
\hline
\end{tabular}

The results of the post hoc test showed exactly between which categories there is a statistically significant difference. Still, the authors wanted to see the value of each category so that they could conclude which category was the most developed or underdeveloped. Therefore, the mean value of each category was calculated. The post hoc test results can be seen below, in Table 2, from which a conclusion can be drawn as to which category is more developed than the others. 
Table 2. Results of post hoc test, showing which category is more developed.

\begin{tabular}{|c|c|c|c|}
\hline Category 1 & Category 2 & $p$-Value & Category 1 vs. Category 2-Mean \\
\hline Culture, informal institutions & Market conditions & 0.02 & $1>2$ \\
\hline Culture, informal institutions & Human capital & 0.01 & $1>2$ \\
\hline Culture, informal institutions & $\begin{array}{l}\text { Knowledge creation and } \\
\text { dissemination }\end{array}$ & 0.00 & $1>2$ \\
\hline Culture, informal institutions & Finance & 0.00 & $1>2$ \\
\hline Culture, informal institutions & Networking and support & 0.02 & $1>2$ \\
\hline Formal institutions, regulations, taxation & Finance & 0.02 & $1>2$ \\
\hline Physical infrastructure & Finance & 0.02 & $1>2$ \\
\hline
\end{tabular}

At the beginning of the analysis, general framework conditions and systemic framework conditions were viewed together in their non-digital and digital dimensions, which is adequate for conducting the analyses mentioned above. In the following, when it was determined between which categories there is a statistically significant difference, the paper's authors focused on the analysis of the least developed categories. Between the alternative to observe the least developed indicators in non-digital dimensions and the alternative to observe the least developed indicators within the digital dimension, the authors decided to observe only the least developed indicators within the digital dimension of the digital entrepreneurial system of the Republic of Serbia. Each category consists of appropriate indicators and questions from the questionnaire, formed based on EIDES research. After determining each statistically significant difference between the two observed categories, the less developed category will be identified; its structure will be presented through a table, and the least developed indicator in its digital dimension will be determined.

Observing Culture, informal institutions, and Market conditions, it is concluded that Culture, informal institutions are a category that is more developed than Market conditions. As mentioned above, each category consists of specific indicators. In Table 3, one can see the indicators that make up Market conditions in the digital dimension.

Given that Market conditions is a less developed category, we wanted to see what the "bottleneck" was within this category. Observing the matrix and finding the least developed indicator within the category of Market conditions in the digital dimension, we concluded that the "bottleneck" in the Market conditions category is T-index, with a value of 0.06 in the Republic of Serbia [26]. The T-index is a percentage of the value that estimates the market share of each country in relation to global e-commerce. The higher the T-index, the greater the potential for e-commerce in a given country. In the Republic of Serbia, the T-index is very low compared to the European Union countries, where it is the highest in Germany, with a value of 5.9. The maximum value of the T-index is 100.

Table 3. The components of market conditions in the digital dimension (the table refers to the Republic of Serbia and was made in the likeness of the EIDES report).

\begin{tabular}{ccc}
\hline \multicolumn{3}{c}{ Market Conditions in the Digital Dimension of the Digital Entrepreneurial System of the Republic of Serbia } \\
\hline Indicator & Indicator Value & Maximum Value \\
\hline $\begin{array}{c}\text { Individuals using the internet for ordering goods or services } \\
\text { Enterprises having received orders via computer-mediated } \\
\text { networks, \% of enterprises }\end{array}$ & 34 [27] & 100 \\
\hline Enterprises total turnover from e-commerce & $26[28]$ & 100 \\
\hline Enterprises turnover from web sales & $9[29]$ & 100 \\
\hline T-index & $9[30]$ & 100 \\
\hline Pay to advertise on the internet & $0.06[26]$ & 100 \\
\hline
\end{tabular}


Then, Culture, informal institutions, and Human capital were observed. It was concluded that Culture, informal institutions was a more developed category compared to Human capital. When looking at Human capital, the least developed indicator is the use of the internet to take online courses, with a value of 5 in the Republic of Serbia [32]. In Table 4, one can see the indicators that make up Human capital in the digital dimension. This indicator implies the use of the internet to attend an online course in any subject. The country with the highest value of this indicator in the European Union is Iceland, where the value is 32 , and the maximum value is 100 .

Table 4. The components of human capital in the digital dimension-the scale-up phase of an enterprise (the table refers to the Republic of Serbia and was made in the likeness of the EIDES report).

\begin{tabular}{ccc}
\hline \multicolumn{3}{c}{ Human Capital in the Digital Dimension of the Digital Entrepreneurial System of the Republic of Serbia } \\
\hline Indicator & Indicator Value & Maximum Value \\
\hline Internet use: finding information for goods and services & 55 [33] & 100 \\
\hline Internet use: doing an online course & 5 [32] & 100 \\
\hline
\end{tabular}

Then, Culture, informal institutions, and Knowledge creation and dissemination were observed, where the category Culture, informal institutions is more developed than Knowledge creation and dissemination. In Table 5, one can see the indicators that make up Knowledge creation and dissemination in the digital dimension. The least developed digital indicator within the Knowledge creation and dissemination category is software developers, with a value of 0.36 in the Republic of Serbia [34]. Software developers represent the number of software developers per 1000 inhabitants. The highest value of this index is in Germany, with 6.56, while the maximum value is 100 .

Table 5. The components knowledge creation and dissemination in the digital dimension—-the startup phase of an enterprise (the table refers to the Republic of Serbia and was made in the likeness of the EIDES report).

Knowledge Creation and Dissemination in the Digital Dimension of the Digital Entrepreneurial System of the Republic of Serbia

\begin{tabular}{ccc}
\hline Indicator & Indicator Value & Maximum Value \\
\hline Employment in high tech and KIBs & $4.5[35]$ & 100 \\
\hline Software developers & $0.36[34]$ & 100 \\
\hline
\end{tabular}

The categories observed next were Culture, informal institutions, and Finance, where it was concluded that Culture, informal institutions is a category that is more developed than the category Finance. In Table 6, one can see the indicators that make up Finance in the digital dimension. It was found that three indicators are underdeveloped within the finance category. As seen below, the Finance category is compared in two more cases with the corresponding categories where there is a statistically significant difference. In this and the following comparison, Formal institutions, regulations, taxation, and Finance will be considered the two least developed indicators of the three least developed indicators within the category of Finance in the digital dimension. We start from the indicators within the digital conditions of Fintech, with a value of 27 in the Republic of Serbia [36]. Fintech represents the number of companies with financial technology per 1,000,000 inhabitants. As a constant maximum value cannot be determined in this indicator, since its limit can be constantly moved, it was observed in relation to the maximum value in the USA, which is 10,605 for financial technology (Fintech). 
Table 6. The components of finance in the digital dimension-the scale-up phase of an enterprise (the table refers to the Republic of Serbia and was made in the likeness of the EIDES report).

Finance in the Digital Dimension of the Digital Entrepreneurial System of the Republic of Serbia

\begin{tabular}{ccc}
\hline Indicator & Indicator Value & Maximum Value \\
\hline Fintech & $27[36]$ & 10,605 \\
\hline
\end{tabular}

Then, the categories Culture, informal institutions, and Networking and supporting were observed. It was concluded that the category Culture, informal institutions, is more developed than Networking and supporting. In Table 7, one can see the indicators that make up Networking and supporting in digital dimension. Observing Networking and supporting within digital conditions, the least developed indicator is the Accelerator amounts, with the value of 0.01 [37]. This is an indicator whose maximum value is 100 . The authors of the EIDES research defined it as an indicator obtained when dividing the number of accelerators of the EU member states and GDP per capita.

Table 7. The components of networking and supporting in the digital dimension-the startup phase of an enterprise (the table refers to the Republic of Serbia and was made in the likeness of the EIDES report).

\begin{tabular}{|c|c|c|}
\hline \multicolumn{3}{|c|}{ Networking and Supporting in the Digital Dimension of the Digital Entrepreneurial System of the Republic of Serbia } \\
\hline Indicator & Indicator Value & Maximum Value \\
\hline Accelerator number & 5 [37] & 43 \\
\hline Accelerator amounts & $0.01[37]$ & 100 \\
\hline Meetup Events/Meetup Tech Group Indicator (MTGI) & $11[38]$ & 100 \\
\hline Meetup Members/Meetup Tech Member indicator (MTMI) & $1.2[38]$ & 10 \\
\hline
\end{tabular}

The categories Formal institutions, regulations, taxation, and Finance were observed as well, where it was concluded that Formal institutions, regulations, taxation was more developed than the Finance category. In Table 8, one can see the indicators that make up Finance in the digital dimension. As highlighted in the comparison of the categories Culture, informal institutions and Finance, in this case, the second least developed indicator within the category Finance in digital conditions will be observed. The first indicator is Alternative Financing 3, as defined by the authors of the EIDES research, with a value of 0.05 in the Republic of Serbia [39]. This indicator represents the volume of European business per million inhabitants and is measured in millions of euros. As in this case, it is impossible to determine the maximum fixed value; the maximum value was observed in the countries of the European Union, where France stood out, with 217.78.

Table 8. The components of Finance in the digital dimension - the startup phase of an enterprise (the table refers to the Republic of Serbia and was made in the likeness of the EIDES report).

Finance in the Digital Dimension of the Digital Entrepreneurial System of the Republic of Serbia

\begin{tabular}{ccc}
\hline Indicator & Indicator Value & Maximum Value \\
\hline Alternative financing 1 & $0.55[40]$ & 4.75 \\
Alternative financing 2 & $0.13[39]$ & 1.63 \\
Alternative financing 3 & $0.05[39]$ & 217.78 \\
Alternative financing 4 & $1.3[41]$ & 2.29 \\
\hline
\end{tabular}

Finally, the categories of Psychical infrastructure and Finance were observed, where it was concluded that the category of Psychical infrastructure is more developed than the category of Finance. In Table 9, one can see the indicators that make up Finance in the digital dimension. As previously explained, the third most developed indicator of the three least developed indicators within the category Finance in digital conditions is 
Alternative Financing 2, where the authors of the EIDES report defined it as the total alternative financing volume per million inhabitants, where the value of the indicator is 0.13 in the Republic of Serbia [39]. In this case, it is also impossible to determine a constant maximum value, so the maximum value of the countries in the European Union, where France stands out, with the maximum value of 1.63 , was taken into account.

Table 9. The components of finance in the digital dimension-the startup phase of an enterprise (the table refers to the Republic of Serbia and was made in the likeness of the EIDES report).

\begin{tabular}{ccc}
\hline \multicolumn{2}{c}{ Finance in the Digital Dimension of the Digital Entrepreneurial System of the } \\
Republic of Serbia
\end{tabular}

Indicators in the digital dimension of the digital entrepreneurial system of the Republic of Serbia that can be singled out as "bottlenecks" are those that, to the highest degree, slow down the development of the digital entrepreneurial system of the Republic of Serbia. These are T-index, Usage of the Internet for online courses, Software developers, Fintech, Accelerator amounts, Alternative financing 3, and Alternative financing 2.

The systemic digital conditions of the digital entrepreneurial system of the Republic of Serbia are less developed than the framework digital conditions. Systemic framework conditions represent different resources available to entrepreneurial enterprises in three phases of the enterprise life cycle-stand-up, startup, and scale-up [2]. In Table 10 it can be seen that digital conditions in startup companies are the most underdeveloped. According to the authors of the EIDES report, this is the phase of starting a business and refers to the actual launch of a new entrepreneurial venture and includes early expertise of the business model [1]. Entrepreneurs in the Republic of Serbia, whose companies are in the startup phase, lack Software developers, Alternative financing, and Accelerators the most. They are immediately followed by digital conditions in companies in the scale-up phase. As the authors of the EIDES report state, the scale-up phase encompasses the scale of these entrepreneurial ventures that have uncovered a solid business model, which is scalable. Entrepreneurs in the Republic of Serbia, who have companies in the scale-up phase, have the greatest difficulties using the internet to conduct online courses and fintech.

Table 10. The least developed indicators of the digital entrepreneurial system of the Republic of Serbia in the digital dimension.

\begin{tabular}{|c|c|c|c|c|}
\hline \multicolumn{5}{|c|}{ General Framework Conditions } \\
\hline & Culture, Informal Institutions & Formal Institutions, Regulations & Market Conditions & Physical Infrastructure \\
\hline \multicolumn{5}{|c|}{ T-index } \\
\hline \multicolumn{5}{|c|}{ Systemic Framework Conditions } \\
\hline & Human Capital, Talent & Knowledge Creations, Dissemination & Finance & Networking and Support \\
\hline \multicolumn{5}{|l|}{ Stand-up } \\
\hline Startup & & Software developers & $\begin{array}{l}\text { Alternative finance } 2 \\
\text { Alternative finance } 3\end{array}$ & Accelerator amounts \\
\hline Scale-up & $\begin{array}{c}\text { Usage of the Internet for online } \\
\text { courses }\end{array}$ & & Fintech & \\
\hline
\end{tabular}

\subsection{Identification of the Pillars of the Digital Entrepreneurial System of the Republic of Serbia}

As mentioned above, the paper's authors used the EIDES report to form a survey for the Republic of Serbia. Based on the EIDES report, the values of each pillar of the digital entrepreneurial system in its digital dimension were calculated. The names of the variables and the designations for them are taken from original research. 
The difference between general framework conditions and systemic framework conditions is that systemic framework conditions are viewed through three phases of the enterprise life cycle. After each pillar is calculated for each stage of the enterprise life cycle, based on the mean values of the observed pillar in three phases, a value will be calculated that will represent the value of the pillar in all three life phases of the enterprise cycle combined.

General Framework Conditions

DFC_P1 = Culture, informal institutions

$$
\begin{gathered}
\text { DFC_P1 }=(\text { DFC_P1_I1 }+ \text { DCP_P1_I2 + DFC_P1_I3 + DFC_P1_I4 }) / 4 \\
\text { DFC_P1 }=(0.74+0.81+0.78+0.84) / 4
\end{gathered}
$$

Culture, informal institutions $=0.79275$

DFC_P2 = Formal Institutions, Regulations and Taxation.

$$
\begin{gathered}
\text { DFC_P2 }=(\text { DFC_P2_I1 + DCP_P2_I2 + DFC_P2_I3 + DFC_P2_I4 + DFC_P2_I5 + DFC_P2_I6 }) / 6 \\
\text { DFC_P2 }=(0.40+0.03+0.16+0.69+0.48+0.74) / 6
\end{gathered}
$$

Formal Institutions, Regulations and Taxation $=0.41587$

DFC_P3 = Market Conditions

$$
\begin{gathered}
\text { DFC_P3 = (DFC_P3_I1 + DCP_P3_I2 + DFC_P3_I3 + DFC_P3_I4 + DFC_P3_I5 + DFC_P3_I6 }) / 6 \\
\text { DFC_P3 }=(0.34+0.26+0.09+0.09+0.00+0.09) / 6 \\
\text { Market Conditions }=0.1451 \\
\text { DFC_P4 }=\text { Physical Infrastructure }
\end{gathered}
$$

$$
\begin{gathered}
\text { DFC_P4 = (DFC_P4_I1 + DCP_P4_I2 + DFC_P4_I3 + DFC_P4_I4 + DFC_P4_I5 + DFC_P4_I6 + DFC_P4_I7) } / 7 \\
\text { DFC_P4 }=(0.29+0.19+0.04+0.06+0.34+1.00+0.93) / 7
\end{gathered}
$$

Physical Infrastructure $=0.406531$

Systemic Framework Conditions

Stand-up

S1_SDC_P1 = Human capital

$$
\begin{gathered}
\text { S1_SDC_P1 = } \\
\text { S1_SDC_P1_I1 + S1_SDC_P1_I2 + S1_SDC_P1_I3 }) / 3 \\
\text { S1_SDC_P1 }=(0.09+0.50+0.46) / 3
\end{gathered}
$$

Human capital $=0.350317$

S1_SDC_P2 $=$ Knowledge Creation and Dissemination

$$
\begin{gathered}
\text { S1_SDC_P2 }=(\text { S1_SDC_P2_I1 + S1_SDC_P2_I2) } / 2 \\
\text { S1_SDC_P2 }=(1.00+0.27) / 2
\end{gathered}
$$


Networking and Support $=0.419167$

Startup

S2_SDC_P1 = Human capital

$$
\begin{gathered}
\text { S2_SDC_P1 }=(\text { S2_SDC_P1_I1 }) / 1 \\
\text { S2_SDC_P1 }=(0.21) / 1
\end{gathered}
$$

Human capital $=0.21$

S2_SDC_P2 = Knowledge Creation and Dissemination

$$
\begin{gathered}
\text { S2_SDC_P2 }=(\text { S2_SDC_P2_I1 + S2_SDC_P2_I2 }) / 2 \\
\text { S2_SDC_P2 }=(0.05+0.00) / 2
\end{gathered}
$$

Knowledge Creation and Dissemination $=0.0243$

S2_SDC_P3 = Finance

$$
\begin{gathered}
\text { S2_SDC_P3 = (S2_SDC_P3_I1 + S2_SDC_P3_I2 + S2_SDC_P3_I3 + S2_SDC_P3_I4 }) / 4 \\
\text { S2_SDC_P3 }=(0.12+0.08+0.00+0.57) / 3 \\
\text { Finance }=0.190865 \\
\text { S2_SDC_P4 }=\text { Networking and Support } \\
\text { S2_SDC_P4 = (S2_SDC_P4_I1 + S2_SDC_P4_I }+ \text { S2_SDC_P4_I3 + S2_SDC_P4_I4 }) / 4 \\
\text { S2_SDC_P4 }=(0.12+0.00+0.11+0.12) / 4
\end{gathered}
$$

Networking and Support $=0.086595$

Scale-up

S3_SDC_P1 = Human capital

$$
\begin{gathered}
\text { S3_SDC_P1 }=(\text { S3_SDC_P1_I1 + S3_SDC_P1_I2 }) / 2 \\
\text { S3_SDC_P1 }=(0.55+0.05) / 2
\end{gathered}
$$

Human capital $=0.3$

S3_SDC_P2 $=$ Knowledge Creation and Dissemination

$$
\begin{gathered}
\text { S3_SDC_P2 }=(\text { S3_SDC_P2_I1 + S3_SDC_P2_I2 }) / 2 \\
\text { S3_SDC_P2 }=(0.29+0.29) / 2
\end{gathered}
$$

Knowledge Creation and Dissemination $=0.29$

S3_SDC_P3 = Finance

$$
\begin{gathered}
\text { S3_SDC_P3 }=(\text { S3_SDC_P3_I1 }) / 1 \\
\text { S3_SDC_P3 }=(0.00) / 1
\end{gathered}
$$

Finance $=0.00$

S3_SDC_P4 = Networking and Support

$$
\begin{gathered}
\text { S3_SDC_P4 }=(\text { S3_SDC_P4_I1 + S3_SDC_P4_I2 }) / 2 \\
\text { S3_SDC_P4 }=(0.13+0.29) / 2
\end{gathered}
$$

Networking and Support $=0.21$

SDC_P1 = Human capital, using (5), (9) and (13) 


$$
\begin{gathered}
\text { SDC_P1 = } \\
\text { S1_SDC_P1 + S2_SDC_P1 + S3_SDC_P1 }) / 3 \\
\text { SDC_P1 }=(0.350317+0.21+0.3) / 3
\end{gathered}
$$

Human capital $=0.286105$

SDC_P2 = Knowledge Creation and Dissemination, using (6), (10) and (14)

$$
\begin{gathered}
\text { SDC_P2 }=(\text { S1_SDC_P2 }+ \text { S2_SDC_P2 + S3_SDC_P2 }) / 3 \\
\text { SDC_P2 }=(0.63495+0.0243+0.29) / 3
\end{gathered}
$$

Knowledge Creation and Dissemination $=0.316416$

SDC_P3 = Finance, using (7), (11) and (15)

$$
\begin{gathered}
\text { SDC_P3 }=(\text { S1_SDC_P3 }+ \text { S2_SDC_P3 }+ \text { S3_SDC_P3 }) / 3 \\
\text { S3_SDC_P3 }=(0.17333+0.190865+0.00) / 3
\end{gathered}
$$

Finance $=0.00$

SDC_P4 = Networking and Support, using (8), (12) and (16)

$$
\begin{gathered}
\text { SDC_P4 }=(\text { S1_SDC_P4_+ S2_SDC_P4 + S3_SDC_P4 }) / 3 \\
\text { S3_SDC_P4 }=(0.419167+0.086595+0.21) / 3
\end{gathered}
$$

Networking and Support $=0.21$

Based on the mathematical calculation above and Table 11, it is concluded that the Finance pillar of the digital entrepreneurial system is the least developed in its digital dimension, with a value of 0.12224 .

Table 11. The pillars of the digital entrepreneurial system of the Republic of Serbia, in their digital dimension, with the identification of the least developed pillar.

\begin{tabular}{cc}
\hline \multicolumn{2}{c}{ Digital Pillars of the Digital Entrepreneurial System of the Republic of Serbia } \\
\hline Pillar & Pillar Value \\
\hline Culture and Informal Institutions & 0.79275 \\
\hline Formal Institutions, Regulations and Taxation & 0.41586 \\
\hline Market Conditions & 0.14510 \\
\hline Physical Infrastructure & 0.40653 \\
\hline Human Capital & 0.28610 \\
\hline Knowledge Creation and Dissemination & 0.31641 \\
\hline Finance & 0.12224 \\
\hline Networking and Support & 0.23858 \\
\hline
\end{tabular}

All values in the table are normalized, where the lowest value is 0 , while the highest is 1 , making it easier for the reader to understand how weak or strong each pillar is.

\section{Discussion}

The Republic of Serbia, according to the Statistical Office of the Republic of Serbia, and according to the 2019 census, has 6,945,235 inhabitants [42]. According to the World Bank, GDP per capita for 2020 is USD 7673, or 755,335 Serbian dinars [43].

As shown in Figure 1 and Table 11, the following classification of the pillars of the digital entrepreneurial system of the Republic of Serbia, observed in its digital dimension, from the least developed to the most developed, can be made: 
- Finance;

- Market conditions;

- Networking and support;

- Human capital;

- Knowledge creation and dissemination;

- Physical infrastructure;

- Formal institutions;

- Culture and informal institutions.

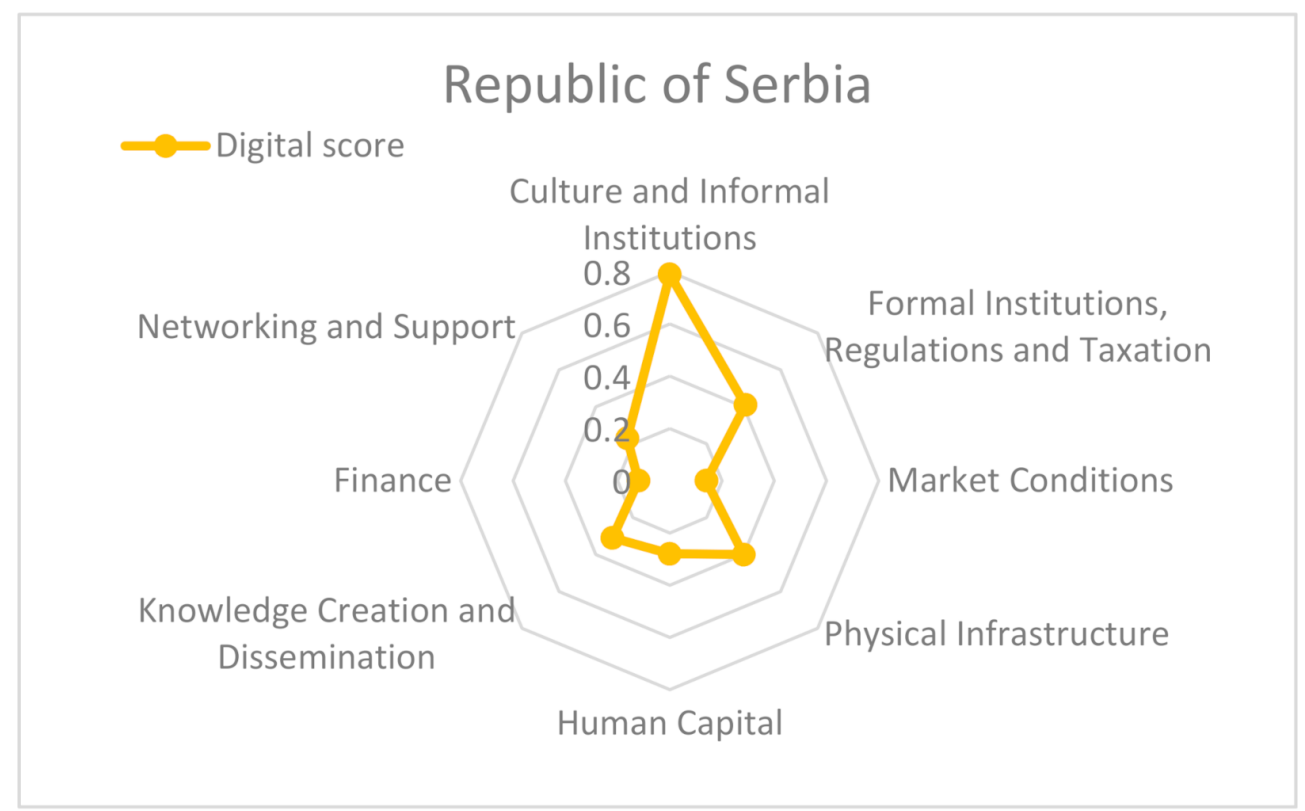

Figure 1. Values of pillars in the digital entrepreneurial system of the Republic of Serbia, in their digital dimension.

Evaluation of the digital entrepreneurial system of the Republic of Serbia in its digital dimension is calculated as a mean value and is 34, while the highest score is 100.

Finances affect the availability of different forms of financing for new ventures. As it could be concluded from the previous part where the least developed indicators within the category of Finance were analyzed, entrepreneurs in the Republic of Serbia have the biggest problem with alternative financing and fintech. There are not enough available alternative sources of funding in the Republic of Serbia, which would help entrepreneurs in the startup and scale-up phase of their entrepreneurial business ventures to overcome the crises that await them. On the other hand, Fintech, as a symbiosis of technologies and customer services for the financial market, is also a "bottleneck" of the digital entrepreneurial system of the Republic of Serbia. It can be concluded that Finance is the primary field in which policymakers should work to enable further development of the digital entrepreneurial system of the Republic of Serbia.

The most developed pillar of the digital entrepreneurial system of the Republic of Serbia, in its digital dimension, is Culture, informal institutions, that is, a group of indicators that affect the individual attitude towards entrepreneurship as a career choice.

Comparing the digital dimension of digital entrepreneurial systems of the EU member states, from the EIDES report, it is concluded that the Republic of Serbia is lagging behind the EU member states. In Table 12, you can see where the Republic of Serbia is compared to the European Union member states. 
Table 12. Comparison of the Republic of Serbia and EU member states, based on the digital entrepreneurial system.

\begin{tabular}{cc}
\hline Digital Entrepreneurial System, Viewed in the Digital Dimension \\
\hline Country & Score \\
\hline Republic of Serbia & 34.0 \\
Greece & 47.4 \\
Bulgaria & 47.8 \\
Romania & 50.5 \\
Croatia & 54.4 \\
Italy & 55.6 \\
Portugal & 56.5 \\
Latvia & 57.2 \\
Poland & 57.2 \\
Cyprus & 58.2 \\
Slovakia & 58.8 \\
Hungary & 59.9 \\
Slovenia & 62.1 \\
Spain & 65.8 \\
Czech Republic & 66.1 \\
Lithuania & 66.6 \\
France & 67.1 \\
Austria & 70.1 \\
Malta & 70.8 \\
Ireland & 73.7 \\
Belgium & 73.8 \\
Estonia & 74.4 \\
Germany & 78.7 \\
Finland & 81.3 \\
Luxembourg & 81.8 \\
Denmark & 83.4 \\
United Kingdom & 85.1 \\
Sweden & 85.2 \\
The Netherlands & 86.3 \\
\hline
\end{tabular}

The authors of this research focused on the digital dimension of the digital entrepreneurial system of the Republic of Serbia. Still, it is recommended that the entrepreneurial system policy consider both stand-up, startup and scale-up comprehensively and consider the dynamics of the ecosystem as a whole.

Once the "bottlenecks" of the digital entrepreneurial system have been identified, they must actively involve all ecosystem stakeholders for entrepreneurial ecosystem policies to be successful. Entrepreneurial ecosystem policies require a long-term approach.

The policy approach to the entrepreneurial ecosystem is likely to pose significant challenges to policy-making and implementation institutions as they are in many cases shaped in the traditional way of decision-making. One of the proposals for overcoming this problem is to form partnerships with regional organizations, which have the authority and are sufficiently committed to undertaking long-term processes to help improve entrepreneurial ecosystems.

The authors propose several solutions for the successful implementation of the improvement of entrepreneurial ecosystems:

- To combine regional and national approaches;

- That the structures and processes of the entrepreneurial ecosystem differ at different levels of policy implementation;

- To foster learning and exchange of experiences across the region;

- To approach the entrepreneurial ecosystem in such a way as to understand how entrepreneurial ecosystems work [44]. 
As mentioned at the outset, entrepreneurial ecosystems are driven by the process of digitalization and close coordination between the entrepreneurial ecosystem and digitalization policies is needed.

\section{Conclusions}

Entrepreneurial ecosystems can be viewed as systems whose purpose is to enable and facilitate the allocation of resources for productive purposes. They are made possible by the ubiquitous trend of digitalization, which is advancing day by day and constantly opens up opportunities to re-examine an organization and whether it creates new values in the digital economy through innovations in its business model. This is precisely the feature that makes entrepreneurial ecosystems a key driver of progress towards the digital economy [4].

The characteristics of the entrepreneurial ecosystem make the entrepreneurial ecosystem a vital policy challenge because the entrepreneurial ecosystem should be viewed as a systemic process, the dynamics of which are not easy to reduce to actions at the enterprise level, which can be easily concluded from the presented research.

Entrepreneurial ecosystems can be understood as a process that is mainly observed at the regional level. They consist of regional stakeholders and resources that specialize in facilitating the assessment of stand-up, startup, and scale-up of new ventures. Since the authors of the EIDES report took into account that this regional dimension is unavailable due to lack of supplements, they formed an EIDES score based on pillars grouped into general and systemic framework conditions governing entrepreneurial ecosystem dynamics. As general conditions represent conditions at the national level that are more or less similarly applied to all regional clusters, they are better suited for resolution at the state level. Systemic conditions tend to show more regional variations because they represent the characteristics of regional communities. That is why the EIDES index measures both types of conditions. It uses data at the national level for general conditions and actions at the regional level to solve systemic framework conditions, which was an excellent starting point for researching the digital entrepreneurial system of Serbia.

Author Contributions: Conceptualization, J.R., Đ.Ć. and B.D.; methodology, J.Ć.; software, D.S.; validation, J.R., D.S. and B.D.; formal analysis, Đ.Ć.; investigation, J.Ć.; resources, B.D. and J.Ć.; data curation, D.S.; writing-original draft preparation, J.R.; writing-review and editing, Đ.Ć.; visualization, B.D.; supervision, D.S.; project administration, J.R. All authors have read and agreed to the published version of the manuscript.

Funding: This research received no external funding.

Institutional Review Board Statement: Not applicable.

Informed Consent Statement: Not applicable.

Data Availability Statement: Data is contained within the article.

Conflicts of Interest: The authors declare no conflict of interest.

\section{References}

1. Autio, E.; Szerb, L.; Komlósi, E.; Tiszberger, M. EIDES 2019-The European Index of Digital Entrepreneurship Systems; EUR 29892 EN; Publications Office of the European Union: Luxembourg, 2019; ISBN 978-92-76-12269-2. [CrossRef]

2. Autio, E.; Rannikko, H. Entrepreneurial Dynamic of the Digital Economy and Finland's International Competitiveness. In Publications of the Government's Analysis, Assessment and Research Activities; Prime Minister's Office, Ed.; Prime Minister's Office: Helsinki, Finland, 2017.

3. Carlsson, B. The Digital Economy: What is new and what is not? Struct. Chang. Econ. Dyn. 2004, 15, 245-264. [CrossRef]

4. Autio, E.; Nambisan, S.; Thomas, L.; Wright, M. Digital affordances, spatial affordances, and the genesis of entrepreneurial ecosystems. Strateg. Entrep. J. 2017, 12, 72-95. [CrossRef]

5. Hair, N.; Wetsch, L.; Hull, C.; Perotti, V.; Hung, Y.-T. Market orientation digital entrepreneurship: Advantages and challenges web 2.0 networked world. Int. J. Innov. Technol. Manag. 2012, 9, 1-17. [CrossRef]

6. Guthrie, C. The digital factory: A hands-on learning project digital entrepreneurship. J. Entrep. Educ. 2014, 17, 115-133. 
7. Le Dinh, T.; Vu, M.C.; Ayayi, A. Towards a living lab for promoting the digital entrepreneurship process. Int. J. Entrep. 2018, 22, 1-17.

8. Davidson, E.; Vaast, E. Digital entrepreneurship and its Sociomaterial enactment. In Proceedings of the 43rd Hawaii International Conference on System Sciences, Koloa, HI, USA, 5-8 January 2010.

9. Millman, C.; Wong, W.-C.; Li, Z.; Matlay, H. Educating students for e-entrepreneurship in the UK, the USA, and China. Ind. High Educ. 2009, 23, 243-252. [CrossRef]

10. Autio, E.; Cao, S.; Temsiripoj, W.; Guntasopatr, P.; Kaensup, P.; Chumjit, S. Enhancing Thailand's Ecosystems for Entrepreneurship; King Mongkut University of Technology: Bangkok, Thailand, 2018.

11. Stam, E. The Dutch Entrepreneurial Ecosystem. SSRN. 2014. Available online: https:/ / ssrn.com/abstract=2473475 (accessed on 31 March 2021).

12. Szerb, L.; Acs, Z.; Autio, E.; Ortega-Argiles, E.; Komplosi, E. REDI: The Regional Entrepreneurship and Development Index-Measuring Regional Entrepreneurship, 1st ed.; European Commission, Directorate-General for Regional and Urban Policy, Publications Office of the European Union: Luxembourg, 2014.

13. Audretsch, D.; Link, A. Valuing an entrepreneurial enterprise. In Concise Guide to Entrepreneurship, Technology, and Innovation, 1st ed.; Audretsch, D., Hayter, S., Link, N.A., Eds.; Edward Elgar: Chelterham, PA, USA, 2015.

14. Stam, E.; Nooteboom, B. Entrepreneurship, innovation and institutions. In Handbook of Research on Innovation and Entrepreneurship, 1st ed.; Audretsch, D., Falck, O., Hevlich, S., Eds.; Edward Elgar: Cheltenham, PA, USA, 2011; pp. 421-436.

15. Foster, G.; Shimizu, C.; Ciesinski, S.; Davila, A.; Hassan, S.; Jia, N.; Morris, R. Entrepreneurial ecosystems around the globe and company growth dynamics. In World Economic Forum; World Economic Forum: Geneva, Switzerland, 2013; Volume 11, pp. 1-36.

16. Audretsch, D.; Lehmann, E. The Seven Secrets of Germany: Economic Resilience in an Era of Global Turbulence, 1st ed.; Oxford University Press: Oxford, UK, 2016.

17. Szerb, L.; Acs, Z.; Komlosi, E.; Ortega-Argiles, R. Discussion Paper-Measuring Entrepreneurial Ecosystems: The Regional Entrepreneurship and Development Index (REDI). Discussion Paper Number: CFE-2015-02. 2015. Available online: http:/ / citeseerx.ist. psu.edu/viewdoc/download?doi=10.1.1.724.3755\&rep=rep1\&type=pdf (accessed on 31 December 2020).

18. Spigel, B. The relational organization of entrepreneurial ecosystem. Entrep. Theory Pract. 2017, 41, 49-72. [CrossRef]

19. Matthews, C.H.; Brueggemann, R.F. Innovation entrepreneurship a competency framework. In Innovation and Entrepreneurship: A Competency Framework; Routledge: New York, NY, USA, 2015.

20. Acs, Z.; Szerb, L.; Lloyd, A. Global Entrepreneurship Index Powered by GEDI; CreateSpace Independent Publishing Platform: Washington, DC, USA, 2018.

21. Elia, G.; Margherita, A.; Passiante, G. Digital entrepreneurship ecosystem: How digital technologies and collective intelligence are reshaping the entrepreneurial process. Technol. Forecast. Soc. Chang. 2020, 150, 119791. [CrossRef]

22. Acs, Z.J.; Autio, E.; Szerb, L. National Systems of Entrepreneurship: Measurement Issues and Policy Implications. Res. Policy 2014, 43, 476-494. [CrossRef]

23. Autio, E.; Szerb, L.; Komlósi, E.; Tiszberger, M. The European Index of Digital Entrepreneurship Systems; EUR 29309 EN; Publications Office of the European Union: Luxembourg, 2018; p. JRC112439. ISBN 978-92-79-91303-7. [CrossRef]

24. Autio, E.; Wright, M. Entrepreneurial innovation: The importance of context. Res. Policy 2014, 43, 1097-1108. [CrossRef]

25. Dillman, D.A. Mail and Internet Surveys: The Tailored Design Method-2007 Update with New Internet, Visual, and Mixed-Mote Guide; John Wiley \& Sons: New York, NY, USA, 2011.

26. Translated. The Top Countries for Online Sales. Available online: https://translated.com/languages-that-matter (accessed on 5 April 2021).

27. Eurostat. Individuals Using the Internet for Ordering Goods or Services. Available online: https://ec.europa.eu/eurostat/ databrowser/view/tin00096/default/table?lang=en (accessed on 5 April 2021).

28. Eurostat. E-Commerce Sales. Available online: https://appsso.eurostat.ec.europa.eu/nui/show.do?dataset=isoc_ec_eseln2 \&lang=en (accessed on 5 April 2021).

29. Eurostat. Share of Enterprises' Turnover on E-Commerce-\%. Available online: https://ec.europa.eu/eurostat/databrowser/ view/tin00110/default/table?lang=en (accessed on 5 April 2021).

30. Eurostat. Enterprises Turnover from Web Sales. Available online: https://appsso.eurostat.ec.europa.eu/nui/setupModifyTableLayout. do (accessed on 5 April 2021).

31. Eurostat. Value of E-Commerce Sales. Available online: https://appsso.eurostat.ec.europa.eu/nui/submitViewTableAction.do (accessed on 5 April 2021).

32. Eurostat. Individuals Using the Internet for Doing an Online Course. Available online: https://ec.europa.eu/eurostat/ databrowser/view/tin00103/default/table?lang=en (accessed on 5 April 2021).

33. Eurostat. Individuals Using the Internet for Finding Information about Goods and Services. Available online: https://ec.europa. eu/eurostat/databrowser/view/tin00095/default/table?lang=en (accessed on 5 April 2021).

34. Stack Overflow. Developer Survey Results. Available online: https://insights.stackoverflow.com/survey/2018 (accessed on 5 April 2021).

35. Eurostat. Employment in High Tech and KIBs. Available online: http:/ / ec.europa.eu/eurostat/tgm/table.do?tab=table\&init=1\& laguage $=$ en $\&$ pcode $=$ tsc00011\&plugin $=1$ (accessed on 5 April 2021). 
36. Deal Room. Fintech. Available online: https://app.dealroom.co/companies/f/_10/anyof_2017)/industries/anyof_fintech/ locations/anyof_Europe\%20(20_Serbia (accessed on 5 April 2021).

37. Startup Blink. Accelerator Amounts. Available online: https://www.startupblink.com/accelerators/serbia (accessed on 5 April 2021).

38. Meet Up. Dive In! There Are So Many Things to Do on Meetup. Available online: https://www.meetup.com (accessed on 5 April 2021).

39. Ziegler, T.; Shneor, R.; Garvey, K.; Wenzlaff, K.; Yerolemou, N.; Rui, H.; Zhang, B. Expanding Horizons: The 3rd European Alternative Finance Industry Report. SSRN Electron. J 2018. Available online: https: / /ssrn.com/abstract=3106911 (accessed on 31 January 2021). [CrossRef]

40. Zhang, B.; Wardrop, R.; Ziegler, T.; Lui, A.; Burton, J.; James, A.; Garvey, K. Sustaining Momentum: The 2nd European Alternative Finance Industry Report; Cambridge Centre for Alternative Finance: Cambridge, UK, 2016; Available online: https:/ / www.jbs.cam.ac.uk/fileadmin/user_upload/research/centres/alternative-finance/downloads/2016-europeanalternative-finance-report-sustaining-momentum.pdf (accessed on 5 April 2021).

41. Statista. Alternative Financing-Serbia. Available online: https://www.statista.com/outlook/dmo/fintech/alternativefinancing/serbia (accessed on 5 April 2021).

42. Republic Statistical Office of the Republic of Serbia. Procene Stanovništva. Available online: https://www.stat.gov.rs/sr-Latn/ oblasti/stanovnistvo/procene-stanovnistva (accessed on 5 April 2021).

43. World Bank. The World Bank in Serbia. Available online: https://www.worldbank.org/en/country/serbia/overview (accessed on 5 April 2021).

44. Autio, E.; Rannikko, H. Retaining winners: Can policy boost high-growth entrepreneurship? Res. Policy 2016, 45, 42-55. [CrossRef] 